\title{
CREOLE: INSIDE. \\ Cómo hacer filmaciones no etnográficas puede servir a la realiza- ción de una etnografía
}

\author{
Dario RANOCCHIARI \\ Universidade de Aveiro (Portugal) \\ darioranocchiari@ugr.es
}

\section{CREOLE: INSIDE. How no-ethnographic filming can help in fieldwork}

Resumen: Durante el trabajo de campo para la realización de mi tesis doctoral he tenido la oportunidad de participar como camarógrafo a la realización de varios videoclips musicales, y como camarógrafo y co-guionista de un documental no etnográfico sobre el más importante grupo de música "típica" de San Andrés, pequeña isla caribeña, punto de cruce y de choque entre el Caribe hispano y el anglófono. En este artículo quiero esbozar unas reflexiones sobre el valor etnográfico y metodológico de esta experiencia supuestamente solo para-antropológica, que sin embargo ha terminado por ser una de las claves fundamentales para la realización de la etnografía.

Abstract: Making fieldwork for my PhD thesis, I had the opportunity to work as cameraman of some musical videos, and cameraman and co-scriptwriter of a no-ethnographic documentary film about the most important "typical" group of San Andrés Island (a frontier between the English and the Hispanic Caribbean). In this text I would like to meditate about the ethnographic and methodological value of this supposedly para-anthropological experience, which however supplied some of the most important elements of the ethnography I wrote.

Palabras clave: Antropología visual. Etnomusicología. Trabajo de campo. Caribe. Colombia Visual anthropology. Ethnomusicology. Fieldwork. Caribbean. 


\section{Introducción}

He estado yendo y viniendo entre Granada y San Andrés entre 2009 y 2011. En total, un año de trabajo etnográfico en esta pequeña pero muy densamente poblada isla del Caribe Occidental, que pertenece políticamente a Colombia a pesar de que sus habitantes más antiguos -que han elegido autodenominarse Pueblo Raizal-se consideren mucho más cercanos afectiva y culturalmente al Caribe anglófono. El tema general de investigación que me había llevado hasta ahí era el mismo que el de una precedente experiencia etnográfica: las relaciones entre músicas e identidades sociales, y en particular con aquella modalidad de articulación identitaria que llamamos etnicidad.

El archipiélago de San Andrés y Providencia me pareció un lugar privilegiado para entender estas modalidades de relación, pues los que se reconocen desde hace unas décadas como miembros del Pueblo Raizal están tratando de hacer valer los dictámenes de igualdad en la diversidad contenidos en la nueva Constitución de Colombia, después de una larga historia marcada por políticas muy agresivas de asimilación cultural (de "colombianización") que van desde la conversión forzosa al catolicismo, la prohibición de hablar y enseñar en inglés o en creole, a la incentivación irresponsable de la inmigración masiva de colombianos continentales a las islas. Las medidas relacionadas con esta última son las responsables de la actual sobrepoblación de la isla, cuyo delicado ecosistema coralino ha sido comprometido quizás irremediablemente por la presencia, en $27 \mathrm{~km}$ cuadrados, de casi cien mil personas. Un peso demográfico que hace de San Andrés una de las islas más densamente pobladas del mundo. Pero la colombianización ha favorecido, paradójicamente, que el $30 \%$ de esta población hoy se reconozca como perteneciente al Pueblo Raizal, pues la reivindicación de esta identidad étnica para definir a los descendientes del amplio crisol de pobladores anteriores a la colombianización coincide con el surgimiento de movimientos de reivindicación política que siguen existiendo hoy en día, y el más radical de los cuales (el AMEN-SD) en 2007 ha llegado a declarar la independencia del archipiélago.

La música, en estos procesos de etnización, ha jugado papeles significativos como marcador de la raizalidad -aunque no tan importantes como creía al momento de escribir mi proyecto de investigación. Pero no es de ellos que quiero hablar aquí, sino de un aspecto aparentemente secundario del proceso de investigación que ha sido desencadenado por la oportunidad que he tenido de trabajar como fotógrafo, camarógrafo y productor de videoclips musicales y, sobre todo, de un documental no etnográfico sobre el más importante grupo de música "típica" de la isla. En este artículo quiero esbozar unas reflexiones -en realidad, casi unas confesiones- sobre las consecuencias que ha tenido la participación en las citadas filmaciones sobre mi experiencia etnográfica. Unas consecuencias que han terminado por influir profundamente en los resultados de la etnografía, aunque en ella -que aún no he terminado de escribir -ocupen un lugar aparentemente marginal y casi anecdótico.

\section{En el proceso etnográfico}

Por varias razones, siendo la fundamental mi pretensión de ver en primera persona hasta dónde podía llegar y cuáles eran los límites de las herramientas más asentadas en antropología, había diseñado la metodología de la investigación. Mi intención era que ésta reflejara de la mejor manera posible una etnografía clásica, de corte exclusivamente cualitativo y basada en técnicas de construcción de datos etnográficos tales como la observación participante y no participante, entrevistas más o menos estructuradas, conversaciones informales y dirigidas, grupos de discusión, etc. Así, después de una primera estancia exploratoria de dos meses dedicada fundamentalmente a la investigación bibliográfica en los archivos locales, a conversaciones sobre temas generales de la vida isleña con las personas que me daban la oportunidad de charlar con ellas, y a la observación no focalizada de lo que pasaba a mi 
alrededor, me puse a trabajar seriamente en la verdadera tarea del etnógrafo: construir datos etnográficos.

Empecé a marcar entrevistas con personas que consideraba pudieran ser informantes clave sobre ciertos argumentos; planifiqué mis lugares de residencia según el tipo de facilidades de contextos de observación que me proporcionarían y empecé a frecuentar los lugares clave de la vida musical isleña. En fin, hice lo que pude para hacerme una idea los más general posible de la vida cotidiana en San Andrés, de cómo funcionaba el mundo musical local y de cómo se entrelazaba -si es que lo hacía- con los contextos políticos de los movimientos étnicos/sociales raizales. Y para construir datos etnográficos que me servirían para la redacción de la etnografía para mi tesis doctoral: notas en el diario de campo, grabaciones audio de algunas entrevistas y de algunos eventos performáticos musicales, grabaciones audiovisuales de otras performances musicales y no musicales o varios tipos de fotografías. Me fue bastante bien. Al final de los primeros cinco meses de trabajo de campo ya tenía una mole significativa de notas relativamente bien clasificadas, muchas entrevistas grabadas con las fichas escritas que codificaban sus contenidos y una buena cantidad de registros escritos $\mathrm{y}$ audiovisuales sobre performances musicales en contextos muy interesantes para mi objeto de estudio.

Si miro las fechas de creación de los datos etnográficos de los que dispongo y a la lista objetivos que me había planteado en el proyecto, me doy cuenta de que la mayoría de ellos podían considerarse "cumplidos" en base a los datos construidos en aquellos cinco meses. Si de verdad hacer trabajo de campo sirviera para cumplir objetivos como los que yo me había propuesto, en mi caso se habría tratado fundamentalmente de seguir construyendo datos sobre los objetivos todavía por cumplir, hacer las maletas y volver para Granada. Pero todos sabemos, hasta yo lo sabía aun antes de empezar a investigar en San Andrés, que hacer etnografía no significa rellenar las casillas que nos hemos propuesto rellenar antes de desplazarnos adonde hemos decidido hacer trabajo de campo (ya sea nuestra propia casa, la Web o una isla del Caribe). Se trata más bien de construir casillas en un proceso estocástico, y de hacer lo más densa posible a la relación con los sujetos que, con nosotros -aunque casi siempre en una posición de desigualdad respecto a nosotros-, participan en el proceso de la investigación.

Respecto a este último punto yo no había conseguido ir muy lejos. Mis relaciones con las personas con las que he vivido en las diversas estancias de campo y con nuestro entorno social se han vuelto lazos permanentes en mi vida, y ello ha contribuido enormemente a la intensidad con la que yo espero haber comprendido a la forma de vida de los isleños. Sin embargo, no había logrado tejer vínculos emocionales parecidos con los colectivos más implicados con el tema de mi investigación: los militantes raizales y los músicos.

De y sobre ellos tenía una abundancia de datos etnográficos: entrevistas, notas, grabaciones, documentos escritos. Pero no había sabido "hacerme amigo" de ninguno de ellos, ni había sabido frecuentarlos en situaciones diferentes a la cita para una entrevista, una reunión en la iglesia, un ensayo musical, un concierto o una marcha de protesta. En parte esto se debía a mi modo de relacionarme con ellos (las peculiaridades de carácter de quién investiga es algo que muchas veces no viene considerado, pero que influye profundamente en el proceso etnográfico), pero también a la naturaleza de estos colectivos.

Tanto los músicos como los militantes raizales son colectivos transversales en la sociedad sanandresana, y no tienen un ámbito contextual cotidiano de interacción. Tanto sus performances musicales como sus performances político-reivindicativas se realizan muy de vez en cuando en San Andrés, donde el mercado musical es mínimo y se organizan protestas solo en casos excepcionales. Acceder a un contexto de relación más personal con ellos me había sido imposible.

Un encuentro ha contribuido de forma inesperada a mejorar esta situación, aunque por supuesto no a resolverla de forma definitiva. Al verme sacar fotos y grabar video durante 
un festival musical, un muchacho se me acercó pidiéndome si podía sacar unas fotos para el artículo que tenía que preparar para un periódico local. Acepté, y al día siguiente fui con él a la noche de entrega de los Premios Nuestra Identidad - un evento anual de reconocimiento de los artistas isleños más destacados. Desde aquel día empecé a colaborar de forma bastante regular con aquel muchacho, Iván Samir, y con el grupo de animadores de la pequeña productora independiente Cotton Tree Media.

Con Cotton Tree he trabajado como colaborador, fotógrafo y camarógrafo en varios proyectos: un periódico cultural, Newspiepa, y sobretodo algunos videoclips musicales (Egusguiza, 2011a; 2011b; 2011c; 2011d) y un documental sobre el más importante grupo activo de música típica raizal. Escribí en mi cuaderno de campo sobre estos encuentros:

San Andrés, 28.03.2011 -Fui donde Iván, para ver si me consigue una lista de pelaos de dancehall, pero al final no hablamos de eso. Está trabajando con unos chicos que hacen videos, parecen interesantes. La casa de producción se llama Cotton Tree y ya hizo varios videoclips -entre los que el de Obie-P, Pussycat Doll y tiene una tv digital con contenidos interesantes: www.sanandres.tv. Hablamos un poco [...] y me mostraron un buen video de prueba hecho con los de[l grupo musical] Creole: quieren hacer un documental y me pidieron que colaborara. Le dije que yo me metía a pleno en el proyecto, sería genial hacer/tener un producto de este tipo y participar en la producción. Por ahora los ayudaré con unos videoclips que tienen pendientes, de dancehall, pero quedamos para hablar con Félix y los otros de Creole en pocos días.

Tenía bien claro que no se habría tratado de hacer videos etnográficos, de hecho, no me estaba metiendo en la producción de una etnografía visual, sino cogiendo la ocasión de tener acceso a una serie de contextos de interrelación y de artefactos culturales que habría podido utilizar para producir datos etnográficos.

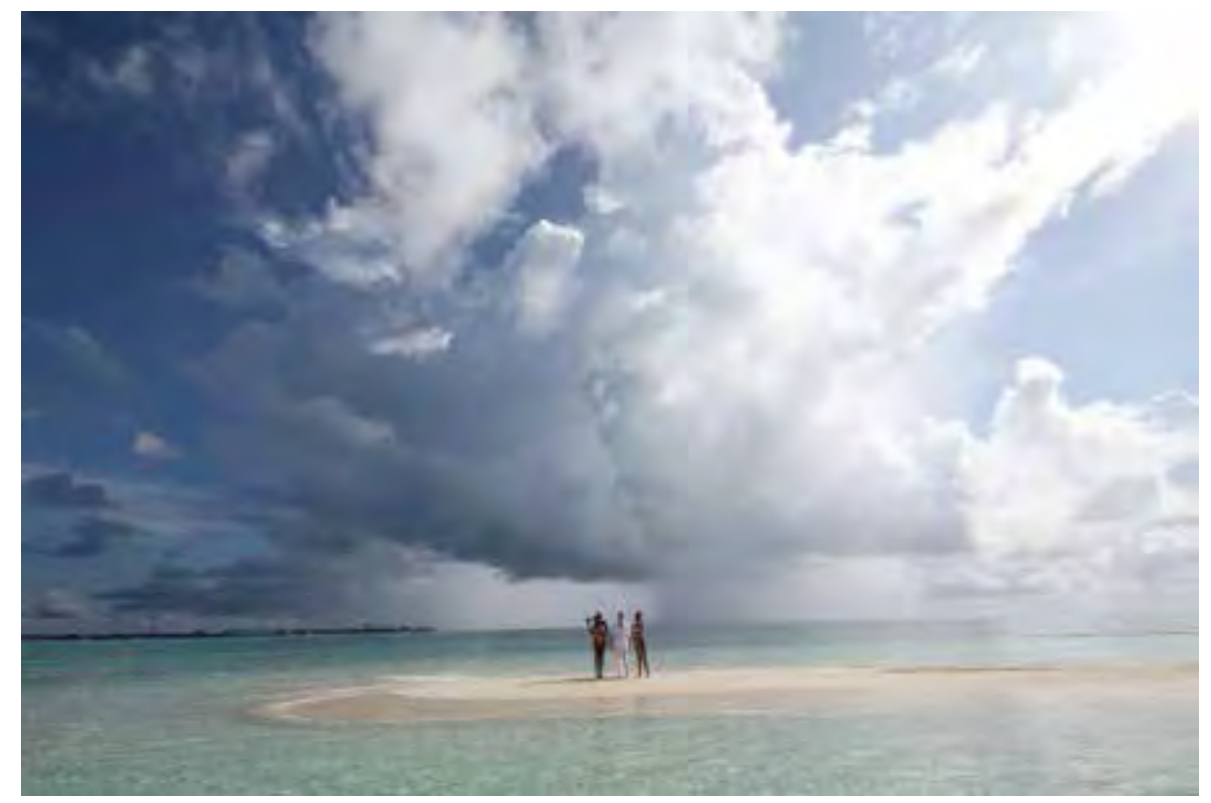

Figura 1. Colombian Party Cartel durante el rodaje de Intocable. (C) Dario Ranocchiari. 
Las sesiones de rodaje de los videoclips me han permitido hacer exactamente lo que me proponía hacer, o sea observación participante desde una perspectiva interna al contexto de producción cultural (como parte de la producción) pero sin que mi presencia participativa lo fuera tanto como para influenciar radicalmente al contexto mismo. Lo que quiero decir es que en tanto fotógrafo de escena o camarógrafo, a pesar de que yo controlaba en parte la composición de las imágenes, operaba bajo los mandos relativamente estrictos del director y del productor. No caben dudas de que sin mí algunos de estos videoclips y algunas de las operaciones de promoción que se hicieron para ellos a partir de mis fotos, habrían sido diferentes. Pero esta diferencia, aunque sea epistemológicamente relevante, no me parecía tan problemática: yo podía influenciar ciertas cosas, ciertas partes del proceso, pero no su lógica general. En la praxis de la investigación era más una oportunidad para aprovechar que un obstáculo a la comprensión. Efectivamente, si no hubiera participado en la producción de aquellos videoclips no habría podido desarrollar mi análisis de la música urbana sanandresana, que constituye un capítulo central de mi etnografía.

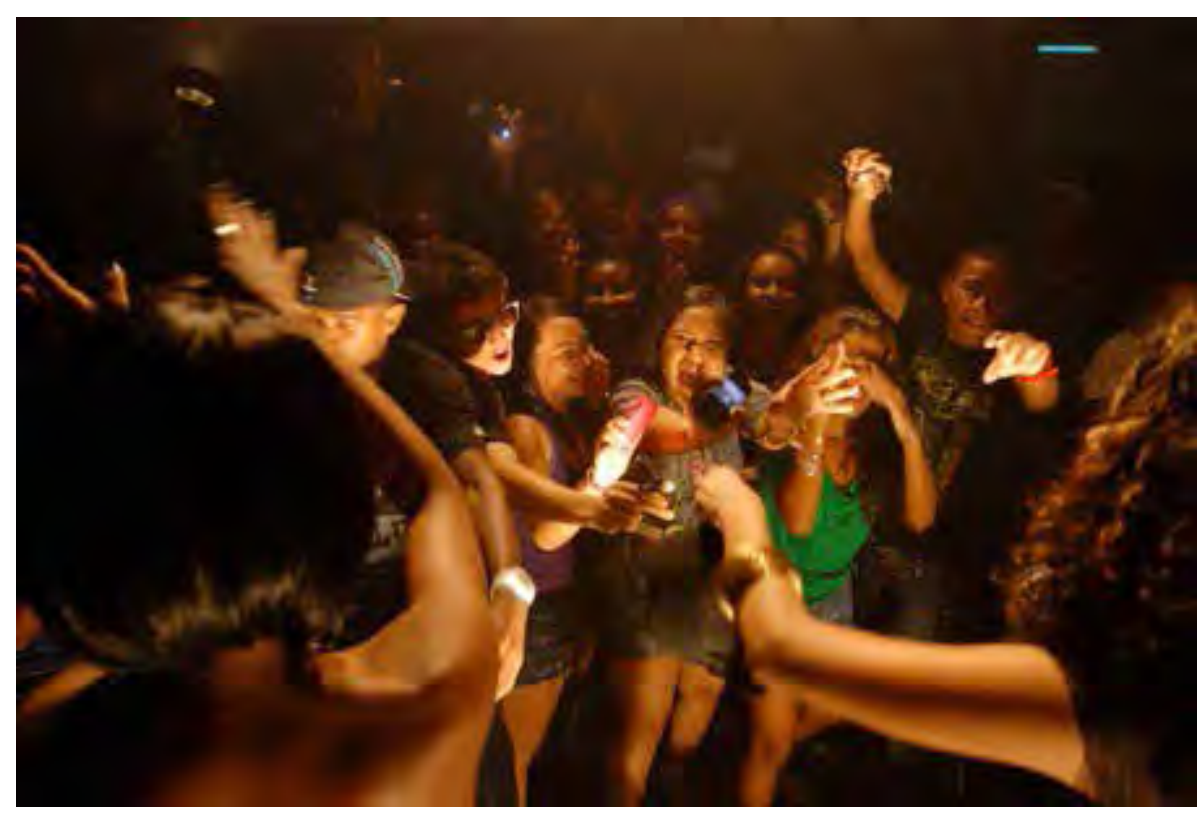

Figura 2. Land Rose durante el rodaje de Te quiero conmigo. (C) Dario Ranocchiari.

Pero ha sido la realización del documental la experiencia más intensa de todo el trabajo de campo, tanto por la duración de su trabajosa y exasperante filmación como por las oportunidades de comprensión y reflexión que me ha proporcionado -por no hablar de las crisis casi existenciales que ha desencadenado, una de las cuales tiene en este texto su anexo más reciente. El documental, que habríamos resuelto llamar Creole: Inside the Island, venía de una idea hasta el momento no realizada de Maki Egusguiza, el director cubano por nacimiento pero sanandresano por matrimonio de todas las producciones audiovisuales de Cotton Tree. Se trataba de contar algunos aspectos de la vida cotidiana de la isla a través de los siete miembros del Creole Group: cada uno de ellos nos habría hablado de sí y nos habría llevado a conocer prácticas culturales que consideraba importante mostrar a quienes no conocían la isla y personas que sentía como cercanas en su experiencia de vida.

A pesar de que era consciente de que no se habría tratado de ningún modo de hacer un documental etnográfico, el tema tratado estaba realmente muy cerca de lo que yo llevaba cinco meses intentando averiguar. Era una ocasión para mi irrepetible de profundizar mi 
relación con los miembros de Creole, filmar documentos que habrían podido revelarse útiles para la etnografía, y entender desde adentro las modalidades de representación de la raizalidad a través de la música, tanto por cómo los miembros de Creole se auto-representaban, como por cómo una productora local de contenidos mediáticos los representaba a ellos.

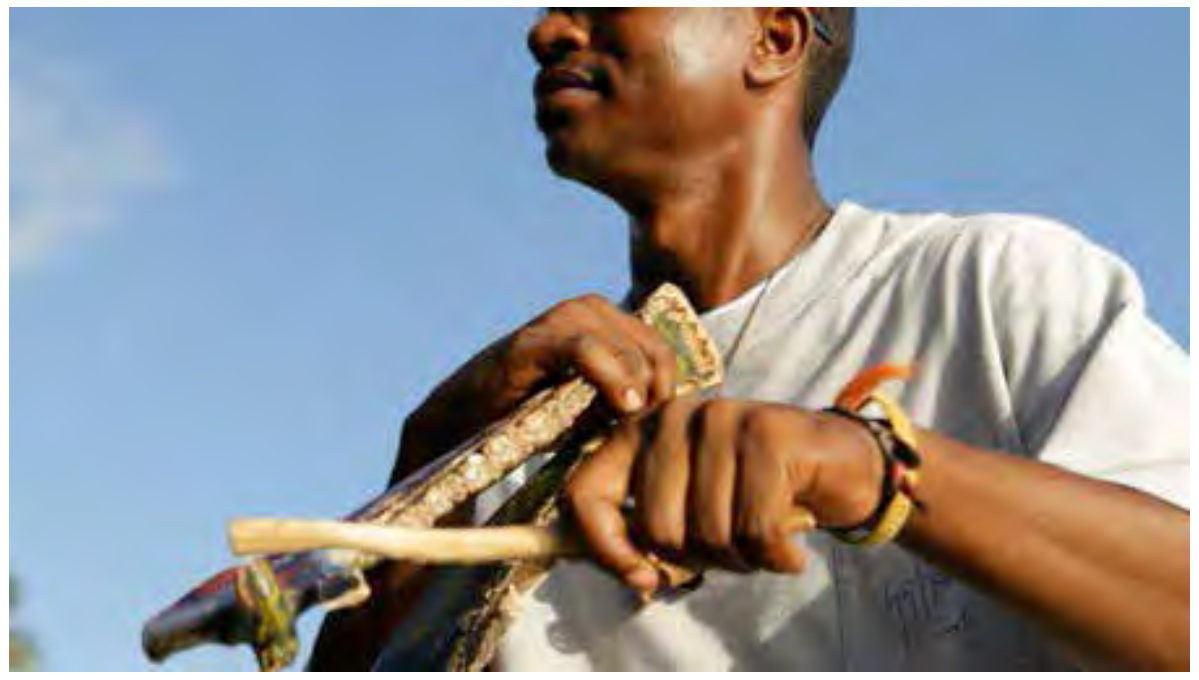

Figura 3. Leodan Greenard (Creole Group) con su jaw-bone. (C) Dario Ranocchiari.

Con relativa rapidez, la realización de Creole: Inside ha empezado a roer a la mayoría de las otras actividades de investigación etnográfica que había ido realizando organizadamente en las primeras dos estancias en la isla. He seguido tomando notas de campo con regularidad, realizando entrevistas, participando en la vida de la isla lo más posible... Esto no significa que haya dejado de hacer las actividades etnográficas planeadas, pero ellas han ido achicándose en mi preocupación mientras el documental se agrandaba cada vez más, captando la mayor parte de mi atención y "desviando" de alguna forma mis acciones hacia los pasos necesarios para la realización del documental. Mi interés en el proyecto aumentaba conforme crecía mi implicación en ello: había empezado queriendo ser sólo uno de los camarógrafos; me había transformado sin quererlo en el único camarógrafo del proyecto; en cierto momento había tenido que implicarme también como co-guionista para que el proyecto no se estancara demasiado; y he terminado como co-director.

Después de un tiempo intentando aclararme qué premisas y qué consecuencias etnográficas tenía mi participación en la realización de Creole: Inside, he resuelto simplemente ignorar el problema y hacer la película de la forma que me pareciera la mejor posible. He dejado de preocuparme de cuestiones de "autenticidad", de que mi intervención en el proceso fuera la mínima necesaria, de que tenía que aceptar cualquier propuesta viniera de los músicos o del otro director, solo porque expresaba algún equivalente del "punto de vista nativo". Me he transformado en uno de los autores del proyecto, en un participante observante más que en un observador participante. Si al comienzo era consciente de que no iba a hacer un film etnográfico, pero que filmando habría podido observar de cerca el contexto etnográfico de producción de aquella específica representación visual -aquella mirada, diría Elisenda Ardèvol (1998) - sobre la identidad y la música típica isleña, llegados a este punto no sabía tampoco cuánto la mirada producida fuera la mía y cuanto la de los otros participantes en el proyecto. Al fin y al cabo, si habíamos empezado cada uno con su objetivo -observar de cerca, el mío; promover su música, el del Creole Group; producir un producto mediático, el de Cotton Tree- habíamos terminado por compartir uno entre todos: que se hiciera el documental. 


\section{Consecuencias etnográficas}

Si en San Andrés he decidido no atender a las consecuencias etnográficas de mi participación al documental, ahora que estoy terminando de escribir la etnografía no puedo sustraerme a esta tarea. Sin dudas, a pesar de que en el sumario más o menos definitivo la reflexión sobre Creole: Inside ocupe apenas un parágrafo, una parte consistente de lo que se expresa en todo el resto del texto ha sido el fruto también de esta experiencia de filmación. $\mathrm{Y}$ esto a varios niveles.

El primero y, quizás, el más obvio y superficial, tiene que ver con el hecho incontestable de que, como en el caso de los videoclips, hoy dispongo de un artefacto cultural (el documental Creole: Inside) que puedo utilizar para construir datos etnográficos. Y no se trata de datos etnográficos cualquiera: tienen que ver profundamente con el argumento de mi tesis (las relaciones música/etnicidad), con un grupo musical que se ha revelado fundamental para su estudio (el Creole Group) y, sobre todo, dispongo de informaciones pormenorizadas sobre los procesos creativos que han llevado hasta ellos.

Un segundo nivel, relacionado como el primero con la construcción de datos etnográficos, tiene que ver con las oportunidades proporcionadas por la gran variedad de contextos de interacción que han sido activados por la filmación en todas sus fases (preproducción, producción y postproducción). Si durante los primeros meses de trabajo de campo solo había sabido realizar entrevistas y conversaciones más o menos formales con la mayoría de los músicos, las muchas sesiones de rodaje y los encuentros de pre-producción me han permitido establecer relaciones relativamente estables y reiteradas tanto con el equipo técnico y con los músicos, como con las personas que participaban o simplemente asistían a las varias fases productivas. En cierto sentido, participar en el documental me ha permitido de verdad, como tendría que hacer con quienes lo vean, conocer la isla de la mano de los miembros de Creole. Por supuesto no la isla "objetiva", que no existe, sino la isla que ellos reputan importante que se conozca y valorice, pero ¿qué hay mejor para un etnógrafo? A través del documental los músicos del grupo han dejado de ser simple "informantes bien informados" y se han vuelto todos porteros etnográficos: me han abierto puertas que habían estado cerradas para mí. A través de uno de ellos he llegado a asistir a las riñas de gallos que se celebran semanalmente en varias galleras más o menos aisladas de la isla y entablar una relación de confianza suficiente para empezar a frecuentar algunos de sus participantes; a través de otro he podido grabar a una anciana mujer cantando una canción de propiciación para una carrera de caballos, practica que se suponía desaparecida; otro me ha presentado a su padre, que se ha revelado un verdadero pozo de "viejas canciones" aunque, cuando lo había entrevistado yo, me había dicho no recordar ninguna.

¿Habría podido obtener lo mismo de ellos también sin participar en el documental? ¿Habría podido lograr los mismos resultados por otros caminos? Probablemente sí, si fuera mejor etnógrafo o si hubiera tenido más suerte. Pero yo solo los he obtenido a través del documental y no creo que sea una casualidad. Por el contrario, creo que es una oportunidad proporcionada por el diferente tipo de relación que se ha establecido entre el etnógrafo yo- y los etnografiados -los músicos, los productores, mi compañero en la dirección. Ya no se trataba de un investigador italiano de una universidad española queriendo saber cosas y observar cosas para después escribirlas en un lenguaje casi incomprensible a los demás en informes que con toda probabilidad ni siquiera llegarían a ser publicados ni leídos en España, imagínense en San Andrés. Se trataba de alguien -siempre un europeo, claro; un blanco, y un universitario, y uno que después de un tiempo se iba a ir, como los otros- que estaba haciendo un video. Para los de Cotton Tree, yo era un colaborador, uno de ellos aunque con fecha de caducidad. Para las personas presentadas por los chicos de Creole y las que directa o indirectamente participaban con ellas, yo era uno que estaba haciendo algo que independientemente de si habría sido un día transmitido o no por la tele local, sabían 
qué era. Para los músicos, era alguien que estaba haciendo algo que les interesaba humana y profesionalmente. Escribía con cierto asombro el día de la primera reunión con Creole:

San Andrés, 11.04.2011 -[...] Respecto al documental, ¡les interesa! ¡Les interesa de verdad! Ya no soy yo que pido el favor de asistir a un ensayo o de hacer una entrevista biográfica. Es significativo que el de hoy haya sido el primer invito a comer run-down $n^{l}$ de parte de un músico que he recibido... y que por una vez sean ellos a pedirme el número de teléfono y no al revés. ¡Veremos!

Y añadía, un mes después:

San Andrés, 10.05.2011 -[...] El punto estratégico principal es: a los músicos les interesa que los graben, que se hagan documentales o videos con/sobre ellos. Tiene que ver indirecta pero profundamente con su oficio. Y no sólo a los músicos: tú te presentas diciendo que quieres hacer una investigación para un libro, o una tesis, o algo, y a nadie le interesa de verdad. Pero si dices que quieres hacer un film, se abren de veras otras puertas.

Recuerdo perfectamente mi sorpresa al darme cuenta que la cámara, una vez enmarcada en un proyecto claramente reconocible por las personas con las que intermediaba, no producía problemas de relación sino los eliminaba. Sabía por otras experiencias que eso pasaba en el cine participativo, pero no era ese el caso. Por supuesto, dependía también del contexto de investigación: no creo que hubiera sido lo mismo si me hubiera centrado en la violencia y el narcotráfico en lugar que en la música, y no ha sido lo mismo cuando he intentado trasladar la experiencia a la militancia raizal (el otro colectivo con el que me habría gustado tener más densidad de relación). Pero el hecho de que a los músicos les interese ser grabados me ha permitido tener con ellos una relación menos asimétrica que si hubiera sido solo un investigador, quizás una relación equivalente en mi campo de estudio -la antropología de las representaciones identitarias- a la de un musicólogo que se pone a tocar junto con los artistas que producen la música que pretende estudiar.

De todos modos, la nueva forma de relación establecida con los alterī (respecto a mí) de la dialéctica de la investigación, me ha sido útil para salir -aunque solo provisionalmentede la jaula conceptual del observador "participante pero no demasiado". Digo provisionalmente porque, si ahora estoy escribiendo sobre eso, evidentemente -y por suerte- la jaula sigue ahí. Durante la investigación, el corto circuito determinado de la necesidad de involucrarme siempre más activamente en el proyecto del documental para que ello pudiera realizarse, me ha obligado a dejar de hacerme preguntas de naturaleza epistemológica sobre la cuestión de la participación y a participar. Ahora me doy cuenta -y esto es otro nivel más de aporte del documental a la etnografía- de que mi participación "irresponsable" no solo me ha obligado a hacer cuentas con los clásicos interrogantes epistemológicos sobre la inevitable influencia del etnógrafo sobre lo que "observa". Me ha proporcionado, más que nada, otra capa más para el análisis etnográfico. Ya no se trata solo de entender las capas emic, con sus complexidades: la mirada de Maki (extranjero residente, casado con una continental de la elite local, interesado sobre todo en los aspectos estéticos/mediáticos del documental) que se cruza con la de Iván (isleño no raizal, hijo de continentales, que quiere valorizar a la música de su tierra) que se cruza con las de cada uno de los músicos de Creole, desde Félix (militante raizal independentista) hasta el Chavo (continental de Cartagena, crecido en San Andrés). Ni solo de hacer que funcione la dialéctica propuesta por Pike (1967) que debería

1 Comida tradicional sanandresana, símbolo de hospitalidad y amistad. 
producir una retroalimentación con las capas etic de la teoría antropológica y de mi punto de vista externo. Una vez que me he metido yo también en el juego, ¿no es emic también mi mirada?

Creo que sí, sobre todo porque mi posición liminoide en el campo de investigación no solo me ha implicado en el proceso de creación de una mirada específica sobre la cultura sanandresana a través de la música, sino que me ha proporcionado un punto de vista que de no haberme implicado simplemente no habría tenido: el de la casa de producción Cotton Tree Media. No me refiero solo a que no habría llegado a conocer con tanta riqueza de matices este aspecto de la producción de sentido sobre y a través de la música -el del mediador entre lo que lo músicos quieren decir/mostrar y lo que se dice/muestra a través de los medias. Me refiero al hecho de que participar directamente en esta mediación me ha dado un punto de vista interno sobre ella, un pasaje fundamental de la articulación entre los procesos creativos locales y el mercado musical nacional y global.

\section{Etnografía y filmación}

Escribiendo este artículo, reflexionando sobre el proceso de filmación de Creole: Inside, no puedo evitar pensar en un cineasta que amo profundamente, Vittorio De Seta. Desde los años 1950s este maestro demasiado poco conocido en el cine italiano ha utilizado en repetidas ocasiones a su cámara como instrumento de interrelación, construyendo sus docufictions a partir del encuentro etnográfico. Nunca ningún libro, ni el Tuhami de Crapanzano con su autoreflexividad exasperante, me ha dado una sensación tan pura de ser de verdad una etnografía como estas películas de De Seta.

Ahora, después de mi infinitamente menos lograda e importante experiencia con Cotton Tree, creo finalmente entender las razones de esta sensación. En el caso de Banditi a Orgosolo, por ejemplo, que es la historia de un pastor sardo que se esconde en los montes de Barbagia después de haber sido injustamente acusado de abigeato y del asesinato de un carabinero, De Seta ha trabajado exclusivamente con actores locales no profesionales: pastores interpretando pastores, en una película con una idea muy general de trama pero carente de guión, que el director construía en el día a día a través de un proceso de negociación continuo con los actores. En Diario di un maestro el único actor profesionales, que interpreta un maestro que no se resigna al abandono escolar de los adolescentes de la escuela de la periferia romana en la que ha sido transferido, estimula en el día a día del rodaje a los jóvenes estudiantes que interpretan a ellos mismos, en un proceso de negociación dialéctica que refleja, dentro de la trama (otra vez, sin un guión cerrado), la negociación ¿externa? del director con el contexto de filmación: la escuela, los actores-estudiantes, el actor profesional (De Seta, 1972).

¿Por qué estas películas de ficción cuentan sobre el encuentro etnográfico más que cualquier ensayo? Por la peculiar forma en la que De Seta, como Jean Rouch, no utiliza a la cámara como instrumento de representación sino de mediación con los sujetos implicados y de estimulación de esta relación. Una relación que, a diferencia de lo que pasa con los textos escritos $^{2}$, es absolutamente imprescindible para la existencia del film porque constituye su propia materia: una película está inevitablemente constituida por un montaje de lo que se ha filmado, de los datos (etnográficos) construidos a través de la cámara. Esto, por supuesto, no significa que sea necesariamente más "objetivo" u "honesto" que un texto escrito en representar a la realidad: ninguno de los dos refleja ni describe nunca a la realidad, sino cuenta la verdad de su lenguaje. El cine, como la etnografía, es ficción: nos los cuentan los antropólogos por lo menos desde aquel famoso seminario de Santa Fe pero lo decía también Rouch en 1975 cuando reivindicaba la necesidad de dejar de un lado cualquier pretensión de objetividad y utilizar a la ficción para hacer etnografías visuales cuales Jaguar o Cocorico

2 Con la parcial pero significativa excepción de los textos de historia oral (se vea, por ej. Portelli, 2005). 
Monsieur Polet (Rouch, 2003 [1975]; 1955; 1974).

Volviendo a Creole: Inside, quizás el mayor valor etnográfico que ha tenido para mi haya sido precisamente su papel de instrumento de mediación del encuentro etnográfico, gracias al que cada uno de los que participamos en la filmación ha contribuido desde su posición subjetiva -que no se reduce a los simples roles de producción-a la negociación continua de una puesta en escena peculiar de la idiosincrasia isleña.

\section{Creole: ¿inside?}

Se me puede objetar, y con todas las razones, que si he escrito este texto es porque algo no ha funcionado en la investigación que he hecho. Si estoy cortando un pelo en cuatro reflexionando sobre cómo grabar un documental no etnográfico haya contribuido a la realización de mi etnografía, probablemente es porque no he sabido hacer etnografía de otra forma: no he sabido hacer que la etnografía misma, de por sí, haya sido suficiente para enlazar una relación densa, lo menos asimétrica posible, con las personas que han compartido conmigo un año de vida en San Andrés. Soy consciente de que algo no cuadra y quizás habría sido mejor si no lo hubiera sabido, ahora que estoy terminando de escribir mi tesis doctoral. $\mathrm{O}$ quizás no.

CREOLE: INSIDE (GUIÓN)

PATIO DE CASA NATIVA. EXTERNO. DIA.

Manos expertas de mujer botan los ingredientes del run-down en una olla. Se oyen voces lejanas hablando en creole, a las que se sobrepone en crescendo una canción de Creole, Aha aha.

CONCIERTO DE CREOLE. EXTERNO. NOCHE.

CREOLE cantando Aha aha.

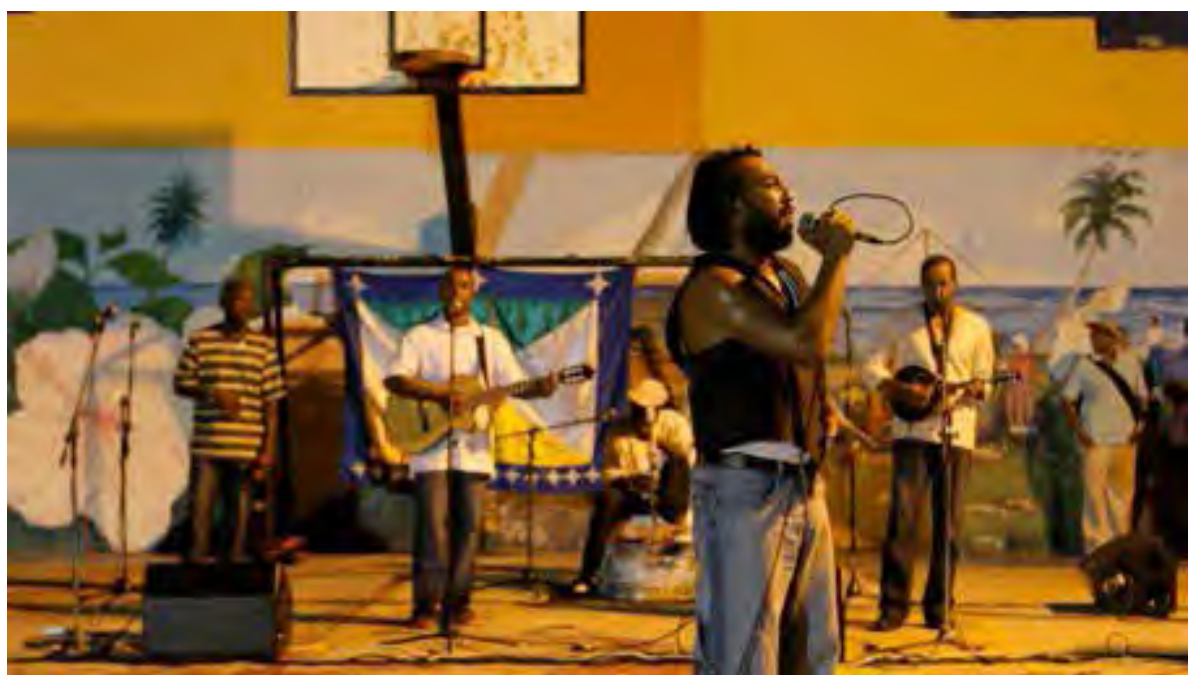

Figura 4. Creole Group, Emancipation Day. (C) Dario Ranocchiari.

PATIO DE CASA NATIVA. EXTERNO. DIA.

Los muchachos de CREOLE están sentados bajo la sombra de los árboles, charlando mientras esperan a la comida. En segundo plano se ve a una COCINERA terminando de llenar los platos de run-down. Todos comen y alguien explica que es esa -sin sillas ni mesa- la manera tradicional de comer run-down: informal, para que todos se sientan a gusto. Mientras todos comen, se oye otra vez Aha aha. 
CONCIERTO DE CREOLE. EXTERNO. DIA.

CREOLE termina Aha aha, y entre los aplausos FELIX explica brevemente al público qué es el grupo Creole.

CASA DE FELIX EN LYNVAL COVE. EXTERNO. DIA.

En el balcón de su casa FELIX, junto con su madre, cuenta como entró en el grupo, su experiencia en ello, etc. Habla de la importancia del grupo para la identidad nativa: el hecho de ser un grupo que no olvida a la tradición, a pesar de todo lo malo que le está pasando a San Andrés en los últimos años. Dice que quiere llevarnos a conocer a alguien.

CALLES DE SAN ANDRÉS. EXTERNO. DIA.

FELIX conduce en moto por el Cove y The Hill, hasta llegar a la Radio Good News, emisora cristiana muy ligada a los movimientos étnicos independentistas raizales.

RADIO GOOD NEWS.

FELIX y BILL FRANCIS hablan de los problemas de San Andrés, de la sobrepoblación, de las políticas de colombianización y del esfuerzo del Pueblo Raizal para reaccionar. Hablan del movimiento AMEN-SD, del que BILL es uno de los portavoces, y de su relación con la First Baptist Church que es "el corazón del pueblo raizal". BILL coge la guitarra e canta una canción suya, Give Me Back My Freedom.

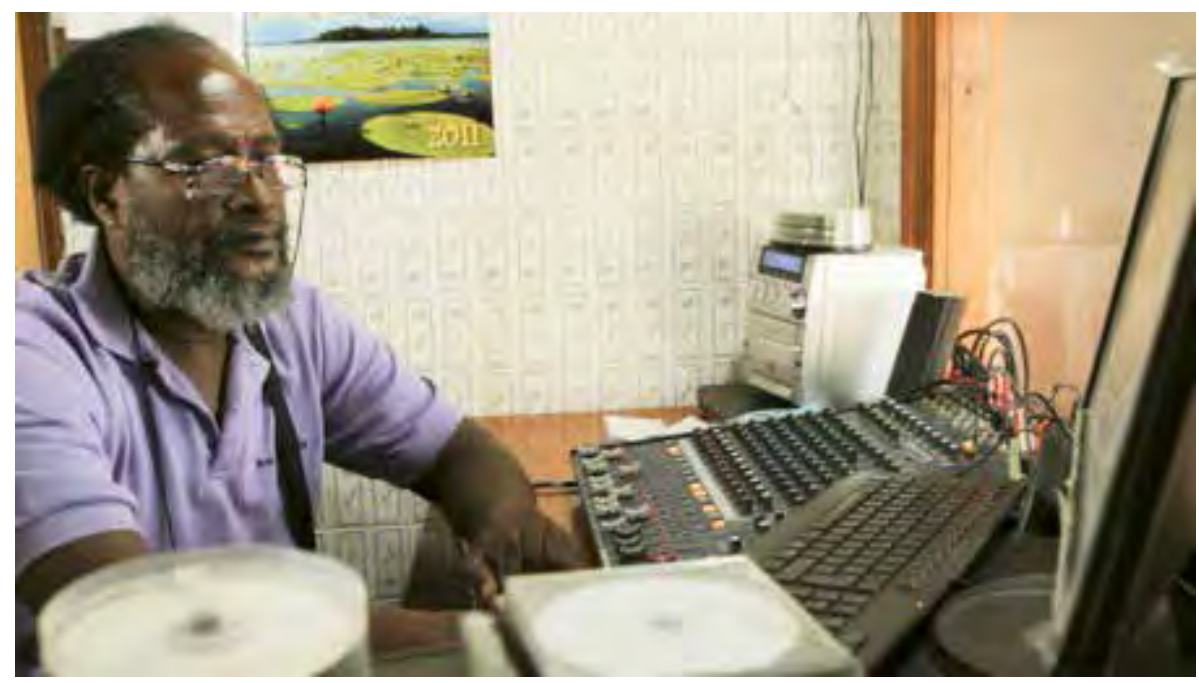

Figura 5. Bill Francis en el estudio de Radio Good News. (C) Dario Ranocchiari.

[DISOLVENCIA CRUZADA]

FIRST BAPTIST CHURCH. INTERNO. DIA.

El CORO de la iglesia está cantando junto con los feligreses. FELIX está entre ellos, y escucha las palabras del sermón del PASTOR HOWARD.

FIRST BAPTIST CHURCH. EXTERNO. DIA.

Panorámica de la iglesia y de los feligreses que se dispersan después de que el culto terminara.

OFICINA FIRST BAPTIST CHURCH. EXTERNO. DIA.

El PASTOR HOWARD, que también es presidente del movimiento raizal AMEN-SD, está esperando en la puerta. FELIX se acerca y lo saluda.

OFICINA FIRST BAPTIST CHURCH. INTERNO. DIA.

Entrevista con el PASTOR HOWARD, que habla de su iglesia, de como el 
primer pastor, Livingston, libertó a los esclavos, y de como la iglesia haya siempre liderado las acciones de inconformidad hacia el dominio colonial colombiano.

CONCIERTO DE CREOLE. EXTERNO. DIA.

CREOLE canta Hold On.

SOUND BAY, PLAYA. EXTERNO. DIA.

El barrio de Sound Bay visto desde la playa: las imágenes subrayan la relación con el mar (ruído de los arrecifes; casas en cima de la arena; ropa tendida en la playa; gente desempeñando faenas cotidianas). ORLYN nos está esperando donde empieza el callejón que conduce desde la playa a la casa de su padre. La casa está vacía, entonces Orlyn nos lleva a "la oficina" del padre: un banco situado de bajo de un almendro, al lado de la carretera.

SOUND BAY, DE BAJO DE UN ALMENDRO. EXTERNO. DIA.

ORLYN habla con su padre, Mr. POZO, que cuenta algo de sí, de su hijo y de los músicos de Sound Bay. Canta algo de una de las 115 canciones que sabe de memoria. ORLYN y POZO hablan de ir a buscar otros músicos ancianos del barrio, los del grupo Bahía Sonora.

SOUND BAY, CIRCUNVALAR. EXTERNO. DIA.

POZO y ORLYN caminan por el sector de Sound Bay. Imágenes del barrio del lado de la circunvalar. Mientras hacen salir a los músicos de sus casas, se oye otra canción de Creole.

SOUND BAY, PLAYA. EXTERNO. DIA.

Los músicos supervivientes de Bahía Sonora, TOMMY, ALFARIO, EUSEBIO Jr. (sustituyendo a su padre, que ya se ha muerto), DONOVAN "BULL", con POZO, hablan y tocan una canción: Donkey Race. Mientras, como si hubiera salido del texto de la canción, un entrenador hace galopar su por la playa.

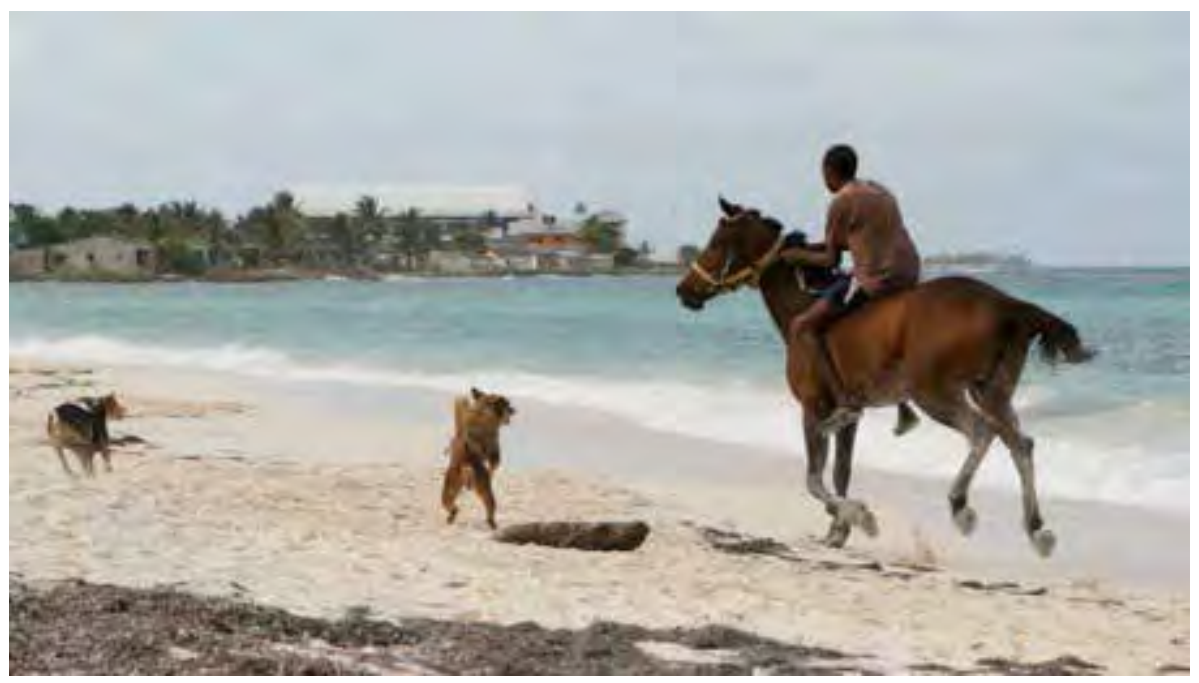

Figura 6. Entrenamiento de caballo en la playa de Sound Bay. (C) Dario Ranocchiari.

SALA ENSAYO DE CREOLE. INTERNO. NOCHE.

CREOLE está empezando el ensayo. Alguien propone que se haga un tema tradicional: es el mismo que han hecho los de Bahia Sonora en la escena precedente. 
CASA DE LEODAN. EXTERNO. DIA.

LEODAN cuenta que su padre era uno de los miembros más importantes de Bahía Sonora, el famoso Lindberg "Bestan" Greenard. Habla de él y de la jawbone, el instrumento hecho con una quijada de caballo que su padre tocaba en Bahía Sonora y él en Creole. Habla de su pasión para el baseball como juego típico de San Andrés, que apasiona más que el futbol a la juventud isleña. Nos invita a ir a un partido del equipo que él entrena.

CANCHA DE TIERRA DE SOUND BAY. EXTERNO. DIA.

El equipo de LEODAN juega con otro equipo de la isla. Enormes pick ups (sound systems) difunden música dancehall, mientras famílias y solteros asisten al juego tomando y bailando. A una esquina de la cancha están unas chabolas llenas de gallos: es la cuerda de FANDOR.

CUERDA DE GALLOS DE FANDOR. EXTERNO. DIA.

El partido se ha acabado. FANDOR, con su gallo favorito en la mano, habla de sí y de su pasión para las riñas. Junto a él está el GALLINERO.

DONDE EL CABALLO DE ALEX. EXTERNO. DIA.

ALEX habla de sí y de su pasión para las carreras de caballos.

CUERDA DE GALLOS DE FANDOR. EXTERNO. NOCHE.

FANDOR y el GALLINERO meten a los gallos en sus transportes y se montan a unas motos, directos hacia la gallera donde se hará la riña de la noche.

DONDE LA CARRERA DE CABALLOS. EXTERNO. DIA.

ALEX nos guía entre la gente: tensión del ambiente durante la espera de la carrera.

GALLERA. INTERNO. NOCHE.

Comienzo de la pelea de un gallo de FANDOR.

DONDE LA CARRERA DE CABALLOS. EXTERNO. DIA.

Comienzo de la carrera de caballos, con ALEX.

GALLERA. INTERNO. NOCHE.

Final de la pelea de un gallo de FANDOR: el gallo mata a su adversario.

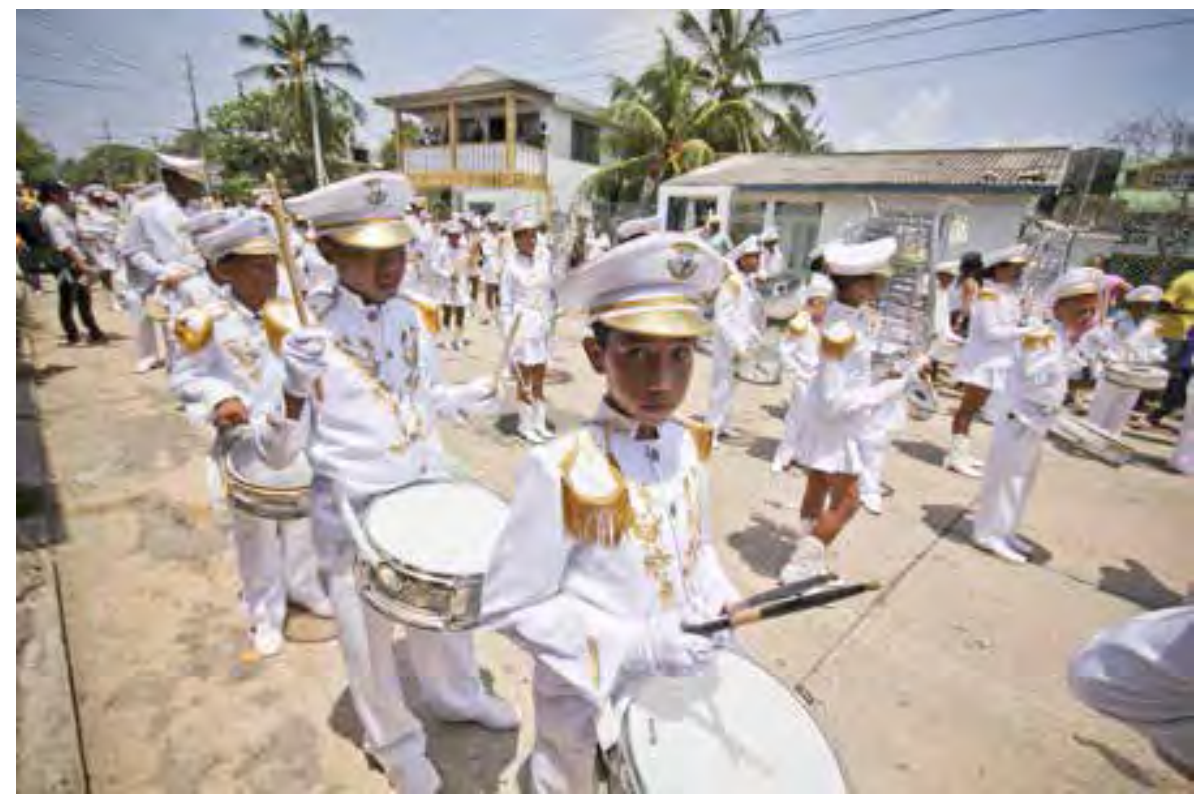

Figura 7. La banda del colegio Natania durante un desfile. (C) Dario Ranocchiari. 
FANDOR y sus COMPAÑEROS están entusiasmados

DONDE LA CARRERA DE CABALLOS. EXTERNO. DIA.

Final de la carrera, con ALEX. El caballo para el que tiene ALEX pierde.

[DISOLVENCIA A NEGRO]

CASA DEL CHAVO. INTERNO. DIA.

Ensayo de CREOLE: el grupo prueba varias canciones, entre las que Little Jenny y Jail Them.

CASA DEL CHAVO. EXTERNO. DIA.

CHAVO cuenta cómo llegó a la isla, cómo entró en el grupo, etc. Cuenta de su banda de salsa, La Rebe, y de los chicos del Colegio Natania que entrena. Nos invita a ir a un ensayo.

BARRIO NATANIA. EXTERNO. DIA.

Vistas del barrio, hasta llegar al Colegio Natania.

COLEGIO NATANIA. INTERNO. DIA.

Ensayo de la banda. Ruido de niños. Impresiones de los niños sobre Chavo y Creole.

DESFILE DEL 20 DE JULIO. EXTERNO. DIA.

La banda del Colegio Natania desfila y gana la competición anual.

CONCIERTO DE CREOLE. EXTERNO. NOCHE.

CREOLE canta Inside.

PATIO DE CASA NATIVA. EXTERNO. DIA.

Mientras se continua escuchando Inside, la COCINERA de la escena 1 y 3 termina de cocinar el run-down y se aleja de la olla con dos platos en las manos, hacia los chicos de CREOLE.

FIN

\title{
Agradecimientos
}

Gracias a la gente de Cotton Tree y al Creole Group por haberme permitido compartir con ellos un año de trabajo de campo. La investigación que está detrás de este artículo ha sido realizada para la escritura de la tesis doctoral Música y etnicidad en la isla de San Andrés, Colombia, dirigida por Ángel Acuña Delgado, y financiada por el programa de Formación de Investigadores en Áreas Deficitarias por Necesidad Docente de la Consejería de Innovación, Ciencia y Empresa de la Junta de Andalucía. Una primera versión del texto ha sido presentada en el I Seminario de Investigación en Antropología Social y Diversidad Cultural (Granada, 5-6 de marzo de 2013). Agradezco también a Inma Antolínez y Luca Sebastiani por haber revisado este texto.

\section{Bibliografía}

\author{
ARDÈVOL, Elisenda \\ 1998 "Por una antropología de la mirada: etnografía, representación y construcción de datos", \\ en Revista de Dialectología y Tradiciones Populares del CSIC, 53 (2): 217-240. \\ BATESON, Gregory \\ 1993 Espíritu y naturaleza: una unidad necesaria (avances en teoría de sistemas, complejidad \\ y ciencias humanas). Buenos Aires: Amorrortu. (Orig. 1979). \\ BERNARD, R. H. \\ 2002 Research Methods in Anthropology. Walnut Creek: Altamira. \\ CLIFFORD, James; MARCUS, George E. (Edits.) \\ 1986 Writing Culture: The Poetics and Politics of Ethnography. Santa Fe: University of Califor- \\ nia Press. \\ CRAPANZANO, Vincent \\ 1985 Tuhami: Portrait of a Moroccan. Chicago: University of Chicago Press.
}


DE SETA, Vittorio (Director)

1961 Banditi a Orgosolo. Película. Titanus: Roma.

DE SETA, Vittorio (Director)

1972 Diario di un maestro. Película televisiva por episodios. RAI: Roma.

EGUSGUIZA, Maki (Director); COLOMBIAN PARTY CARTEL (Artista)

2011a Intocable. Videoclip musical. http://www.youtube.com/watch?v=y84EijXy71w (23-082013).

EGUSGUIZA, Maki (Director); LAND ROSE (Artista)

$2011 \mathrm{~b} T$ Te quiero conmigo. Videoclip musical. http://www.youtube.com/watch? $\mathrm{v}=\mathrm{cYSOw}-$ DToy_4 (23-08-2013).

EGUSGUIZA, Maki (Director); RAYO \& TOBY (Artista)

2011c Movimiento de cadera. Videoclip. http://vimeo.com/28111187 (23-08-2013).

EGUSGUIZA, Maki (Director); RAYO \& TOBY (Artista)

2011d Hot Gial. Videoclip. http://vimeo.com/30703301 (23-08-2013).

PIKE, Kenneth

1967 Language in Relation to a Unified Theory of Human Behaviour. Den Haag: Mouton.

PORTELLI, Alessandro

2005 L'ordine è già stato eseguito. Roma: Donzelli.

PRESIDENCIA DE LA REPÚBLICA

2005 Constitución Política de Colombia. http://web.presidencia.gov.co/constitucion/index.pdf (23-08-2013). (Orig. 1991).

RANOCCHIARI, Dario

2011 "Between the Bairro and the Nation: Performative Identities in Afro-Lusitan Rap Music in Lisbon", en Music and Politics , 5 (1).

ROUCH, Jean (Director)

1974 Cocorico Monsieur Poulet. Película.

ROUCH, Jean (Director)

1955 Jaguar. Película.

ROUCH, Jean (Director)

2003 "The Camera Man”, en Hocking, P. (Comps.). Principles of Visual Anthropology. Den Haag: Mouton. (Orig. 1975). 